\title{
PICTOGRAM-BASED INFORMATION LEAFLET IN PATIENTS WITH PSORIASIS
}

\author{
SWAPNA SATHEENDRAN ${ }^{1}$, ANANTHA NAIK NAGAPPA ${ }^{2}$, SATHISH PAI ${ }^{3 *}$ \\ ${ }^{1}$ Department of Pharmacology, Kasturba Medical College, Manipal University, Manipal - 576 104, Karnataka, India. ${ }^{2}$ Department of \\ Pharmacy Practice, SCS College of Pharmacy Harapanahalli, Karnataka, India. ${ }^{3}$ Department of Dermatology, Kasturba Hospital, Manipal \\ University, Manipal - 576 104, Karnataka, India. Email: drsbpai@yahoo.co.in
}

Received: 30 January 2017, Revised and Accepted: 04 May 2017

\begin{abstract}
Objective: The objective of the study was to evaluate the impact of an information leaflet on the knowledge of disease in patients with psoriasis

Methods: A total of 50 patients with psoriasis on different treatment regimens were selected in the study. The pre- and post-test design (quasiexperimental design) was conducted for user testing of information leaflets (Baker Able design) which covered risk factors, signs and symptoms, and treatment options. The knowledge of psoriasis was assessed before and after the administration of the information leaflet and was compared using paired t-test.
\end{abstract}

Results: At the follow-up interview, it was observed that patients were well informed about their skin disease but had less awareness about the risk factors and methods to cope with the disease. The overall user-testing knowledge assessment mean scores were observed to have significantly improved with $\mathrm{p}<0.001$ after the introduction of the leaflet.

Conclusion: The overall user opinion regarding the content of the leaflets was good. This study shows that an information leaflet given to patients with psoriasis can significantly improve their knowledge of the disease.

Keywords: Patient education, User testing, Psoriasis, Information leaflet.

(C) 2017 The Authors. Published by Innovare Academic Sciences Pvt Ltd. This is an open access article under the CC BY license (http://creativecommons. org/licenses/by/4. 0/) DOI: http://dx.doi.org/10.22159/ajpcr.2017.v10i7.17384

\section{INTRODUCTION}

Verbal communication between patient and physicians is just as important as the manner in which the communication is done between them [1]. Studies have shown that it would be more beneficial if the communication is taken a step ahead with patient information leaflet implemented with pictograms [2]. The implementation of the patient information leaflet in the management of chronic disease will be more helpful in building a therapeutic physician-patient relationship. Many studies have shown that patient education is a means by which physicians can impart information, pertaining to the disease-related lifestyle modification to the patient [3]. Patient education has been identified as one of the major strategies that will help in the management of chronic illnesses like psoriasis [4]. Psoriasis is a chronic illness that affects approximately $2 \%$ of the population. There is a high degree of morbidity which affects the mental status of the patient as well as it affects the appearance of the skin and along with it patients will also have to tolerate the side effects of the prescribed medications. The combined costs of lifelong therapy and amount spent on the disease have a major impact on health-care systems and in general the people of the society. Psoriasis requires a substantial amount of self-management as it has a major impact on the physical and mental aspect of the patient. The patients usually have concerns pertaining to the efficacy of the treatment and adverse effects. Patients usually state that there is inconvenience in the usage of topical application, lack of education pertaining to the disease and the use of medications, inadequate social support, and lack of motivation that may lead to inability to comply to take the medications prescribed [5]. The major shortcoming with selfadministration of medications should be identified and addressed with every patient to increase the compliance and in turn the outcomes of the treatment as well. Furthermore, the positive impact of self-management in psoriasis requires motivating patients to address both the medical and psychosocial aspects of the disease. The betterment of psoriasis is dependent majorly on how the patients manage the disease [5]. In the Indian scenario, after the patient leaves the hospital there is very little anyone can do about how the patients manage their disease. Some patients may be regular in their review visits to the hospital some do not want to come back and follow their own regimen of taking care of the disease along with the medications that have been prescribed to them during their one-time visit with the doctors. This may lead to some people visiting the hospital again with a more exaggerated form of the disease, which will require change in the regimen and in some cases increasing the dose to the control the symptoms of the disease. A few patients may recall the instructions given in the hospital and may follow it religiously. Some studies show that patients are usually adherent to the instructions given about management of the disease, depending on how the instructions are given, like the quality and to the extent to which they understand the instructions [4]. A lot of effort have been put forth by various hospitals on the care of psoriasis. There are leaflets which are primarily in the form of written data and some which are a combination of words and pictures, and these have shown significant improvement of the disease. Some studies have shown that patients could not remember even half of the instructions given to them within a matter of 5 minutes of exiting the hospital. It was also observed that patients have denied any instructions been given at all and even if some patients did agree to the information being provided; they were not able to use the medications as instructed to them [6]. The patient information leaflets serve a series of functions for the patient, which includes the information regarding the disease, for the safety like the contraindications and interactions, how to manage the disease by themselves and what are the risk factors that will exacerbate the disease. These, in turn, will help the patient to manage the disease better and will be made aware of the precautions they can take to help manage the disease. The majority of the patients do not retain the instructions and details given to them by physicians [7]. To provide a patient with information leaflet that will help them with the management of psoriasis is a challenge. To this end, this study was done to study the impact of the leaflet on the management of psoriasis. 


\section{METHODS}

This was a prospective interventional study which was done for 3 months to assess the effect of the patient information leaflet on comprehension and adherence to the instructions given during the stay in the hospital. The study was conducted in the Department of Dermatology, Tertiary Care Hospital, Karnataka, India. All the patients who were admitted and willing to participate were included in the study. The leaflets were translated into local language Kannada in par with readability scores with English leaflets. The translated leaflet was then back translated to English from Kannada by language experts. The back-translated and original versions of leaflets were reviewed. Prior institutional ethical committee permission was obtained for this study from (Ref. No: IEC 253/2013) the hospital.

\section{Information leaflets}

The patient information leaflet was legible which included the risk factors, signs and symptoms, treatment options and details about the disease, the treatment regimens available and its management which was understood by the patient. The readability was determined in the form of a questionnaire, and the scores would help in the determination of the readability. The first day the patients were asked questions followed by which the leaflet was given and 7 days after the initial interaction they were asked the same set of questions, and the score was noted. There were a fixed set of ten multiple choice questions which was asked before and after the implementation of the leaflet. After which a questionnaire for assessing patient's opinion on legibility and content of the leaflet was administered, and the score was recorded. The inclusion criteria were patients of both sexes, age 18-60 years and the exclusion criteria were pregnant and lactating woman and patients with psychiatric illness.

\section{Steps involved in leaflet preparation}

The subject experts reviewed the content of the leaflet. The expert panel constituted of Dermatologists and Clinical Pharmacists. The modifications suggested by the subject experts were implemented before the approval of the current leaflet. The leaflet was drafted and was checked for reliability. Baker able leaflet design (BALD) method was used to assess its layout and design characteristics of the patient information leaflet.

\section{RESULTS}

All the 50 patients were assessed for Kannada version of the questionnaire. The means, user-testing and user-opinion scores of leaflets, and standard deviation scores of Kannada version results are summarized in Table 1. The mean BALD assessment score for Kannada version was 25 .

The overall user-testing knowledge assessment mean scores significantly improved from $29.20 \pm 12.09$ to $65.40 \pm 21.11$ with $p<0.001$. The overall user opinion of legibility and content of the leaflets was good, i.e., $18.02 \pm 3.36$ (Table 2).

Sociodemographic details of the patients: A total of 50 patients were recruited. Out of these 50 patients, 23 patients were with high school educational background and had lower-middle socioeconomic status. The results of sociodemographic details of the patients are briefed in Table 3.

\section{DISCUSSION}

This is a pioneer study in India conducted in patients with psoriasis which involved the testing and usability of pictogram-based patient information leaflets. A study by Thomson et al. recommends that information given verbally to patients should always be accompanied by written and pictorial information which was followed in this study and have shown to be useful for the patient $[8,9]$. The mean BALD score of the Kannada version leaflet used in this study was 25 comparable to other studies with other chronic illness to a score of 24 in a study done by Kavi et al. [10]. There are similar
Table 1: User-testing scores

\begin{tabular}{llll}
\hline $\begin{array}{l}\text { Type of questionnaire } \\
\text { Kannada version }\end{array}$ & Pretest & Post-test & Mean \pm SD \\
\hline User test & $29.20 \pm 12.09$ & $65.40 \pm 21.11$ & $36.20 \pm 9.02$ \\
\hline SD: Standard deviation & & &
\end{tabular}

SD: Standard deviation

Table 2: User opinion scores

\begin{tabular}{lll}
\hline User opinion scores $(n=50)$ & & \\
\hline Opinion of the leaflet & Scores & Mean \pm SD \\
\hline Good & 39 & $18.02 \pm 3.36$ \\
Average & 11 & \\
\hline
\end{tabular}

SD: Standard deviation

Table 3: Sociodemographic details

\begin{tabular}{lll}
\hline Sociodemographic details & Particulars & No of patients \\
\hline Gender & Males & 43 \\
Age & Females & 7 \\
\multirow{2}{*}{ Working status } & $31-50$ & 34 \\
\multirow{3}{*}{ Marital status } & $51-70$ & 16 \\
\multirow{4}{*}{ Social habits } & Working & 45 \\
& Nonworking & 5 \\
& Married & 48 \\
& Unmarried & 2 \\
\multirow{2}{*}{ Educational status } & Smokers & 39 \\
& Nonsmokers & 11 \\
& Alcoholics & 42 \\
Socio-economic status & Nonalcoholics & 8 \\
& Primary school & 8 \\
& Middle school & 19 \\
& High school & 23 \\
& Upper middle & 28 \\
& Lower middle & 14 \\
& Upper lower & 8 \\
\hline
\end{tabular}

studies conducted previously on many chronic illnesses such as hemodialysis, asthma, peptic ulcer, rheumatoid arthritis, and diabetes mellitus which have shown that with the introduction of pictogrambased patient information leaflet, the understanding of the patient regarding the disease is better which was also shown in this study wherein the knowledge assessment scores significantly improved from $29.20 \pm 12.09$ to $65.40 \pm 21.11$ with $p<0.001$ [11]. This study evaluated the readability of the leaflets, which has previously shown to be the precise method that can assess the readability of the leaflets in different languages [12]. The pre- and post-education scores of enrolled patients in a study conducted in the outpatient pharmacy showed a significant improvement in posteducation knowledge scores which was similar to that attained in this study, a drastic improvement from a pre-test core of $29.20 \pm 12.09$ to a post-test score of $65.40 \pm 21.11$ [2]. A study by Humphris showed that patients who have access to the leaflet showed a significant increase in knowledge post-test in comparison to pretest [13].

Another study by Poornima et al. showed that patient education together with information leaflets had a major impact on knowledge, attitude, and practice of the patients toward their disease management. In this study, $78 \%$ of the psoriasis patients have rated the content as good which showed that verbal information provided to the patient itself had a major impact on the patient knowledge. This was implemented with the intention of improving the content of the leaflet and which would be a patient perspective. The patients were asked for their feedback on the opinion of the leaflet at the end of the post-test which showed that the developed leaflet was very useful for the patients which were again comparable to the scores as well as the feedback obtained from the patients [14]. 


\section{CONCLUSION}

This study enlightens us on the importance and the usefulness of a pictogram-based information leaflet. It implies how beneficial it is for the patient and physicians in the management of psoriasis. This platform is underutilized in the hospital and hence must be explored further for chronic diseases like psoriasis. The patient information leaflet can improve and can bring better outcomes in the life of the patients. This will be helpful in many ways one of the most important aspects being the management of the disease once the patients exit the hospital will be easier; second, it will increase the extent of understanding of the patient about the disease and will appreciate the importance of adhering to the medications that will be prescribed.

\section{REFERENCES}

1. Travaline JM, Ruchinskas R, D'Alonzo GE Jr. Patient-physician communication: Why and how. J Am Osteopath Assoc 2005;105(1):13-8.

2. Adepu R, Swamy MK. Development and evaluation of patient information leaflets (PIL) usefulness. Indian $J$ Pharm Sci 2012;74(2):174-8.

3. Bennett MI, Bagnall AM, José Closs S. How effective are patientbased educational interventions in the management of cancer pain? Systematic review and meta-analysis. Pain 2009;143(3):192-9.

4. Jankowiak B, Krajewska-Kulak E, Van Damme-Ostapowicz K, Wronska I, Lukaszuk C, Niczyporuk W, et al. The need for health education among patients with psoriasis. Dermatol Nurs 2004;16(5):439-44.
5. Nestle FO, Kaplan DH, Barker J. Psoriasis. N Engl J Med 2009;361(5):496-509.

6. Busson M, Dunn AP. Patient knowledge about prescribed medicines. Pharm J 1986;236:624-6.

7. Krska J, Morecroft CW. Patients' use of information about medicine side effects in relation to experiences of suspected adverse drug reactions: A cross-sectional survey in medical in-patients. Drug Saf 2013;36(8):673-80.

8. Suhaj A, Mohan KM, Mohapatra AK, Magazine R, Rao CM, Unnikrishnan MK, et al. Development and readability assessment of patient information leaflets for chronic obstructive pulmonary disease. Asian J Pharm Health Sci 2015;5(2):1237-41.

9. Thomson AM, Cunningham SJ, Hunt NP. A comparison of information retention at an initial orthodontic consultation. Eur J Orthod 2001;23:169-78.

10. Priya JK, Balambigai MS, Sariga N, Sathya M, Andhuvan G. Development and validation of patient information leaflet for heart attack patients. Int J Pharm Pharm Sci 2016;8(8):381-3.

11. Hill J, Bird H. The development and evaluation of a drug information leaflet for patients with rheumatoid arthritis. Rheumatology 2003;42:66-70.

12. Roy TR, Sekhar MS, Rodrigues G, Rajesh V. Preparation and readability assessment of patient information leaflets for diabetic foot ulcers. J Soc Health Diabetes 2013;1:7981.

13. Humphris GM, Field EA. An oral cancer information leaflet for smokers in primary care: Results from two randomised controlled trials. Community Dent Oral Epidemiol 2004;32(2):143-9.

14. Poornima D, Ramesh A. Assessment of patient information leaflets usefulness in selected chronic diseases - A South Indian based study. Indian J Pharm Pract 2014;7(1):23-8. 